\title{
Frame-mounted tissue heart valves: technique of construction
}

\author{
IVAN T. BARTEK, MICHAEL P. HOLDEN, a d \\ MARIAN I. IONESCU \\ Department of Cardiothoracic Surgery, The General Infirmary at Leeds and Leeds University
}

\begin{abstract}
Bartek, I. T., Holden, M. P., and Ionescu, M. I. (1974). Thorax, 29, 51-55. Frame-mounted tissue heart valves: technique of construction. The technical details for the construction and preservation of frame-mounted tissue heart valves are described. The results of clinical and experimental work which have prompted changes and improvements in valve construction are briefly discussed.
\end{abstract}

Since the first frame-mounted fascia lata heart valves were used clinically (Ionescu and Ross, 1969), over 260 tissue valves made of autologous or homologous fascia lata or of heterologous pericardium have been inserted at this institution in the mitral, aortic, and tricuspid positions.

Encouraged by our results, especially with aortic valve replacement, over more than four and a half years (Ionescu et al., 1974), we continue the clinical and laboratory testing and evaluation of frame-mounted tissue valves. The experience so far has shown that one important factor on which the long-term function of these valves depends is their perfect construction before insertion (Swales, Holden, Dowson, and Ionescu, 1973).

The technical details for the manufacture and preservation of stented tissue valves are described in this paper. The changes and improvements in construction consequent upon the clinical and laboratory results are discussed.

\section{TECHNIQUES OF VALVE CONSTRUCTION}

The tissues used clinically in our department have been fascia lata and bovine pericardium. With the exception of four cases in which free fascial grafts were used for aortic replacement at the beginning of our experience, all tissue valves were attached to a support frame.

For simplicity the construction of pericardial valves will be described,

THE FRAME The supporting frame consists of a thinwalled, scallop-shaped titanium ring with three narrow

Correspondence to: M. I. Ionescu, Department of Cardiothoracic Surgery, The General Infirmary, Leeds prongs placed at equal distances around the circumference. The ring and prongs are perforated to allow the passage of sutures. The entire frame is covered with a thin layer of woven Dacron velour.

A separate ring of reinforced Silastic, covered on both sides with Dacron velour ${ }^{1}$ is used for attaching the tissue valve to the heart valve annulus (Fig. 1).

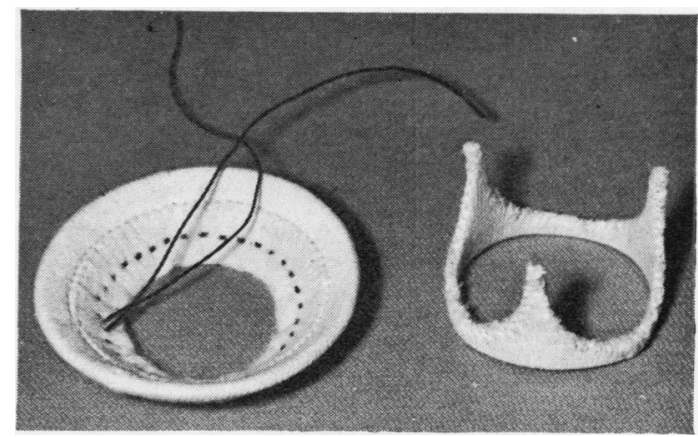

FIG. 1. Dacron-covered titanium (right) and sewing ring (left) for attaching the valve to the heart valve annulus.

Frame size ranges from 16 to $24 \mathrm{~mm}$ inside diameter for aortic valves and from 22 to $30 \mathrm{~mm}$ for mitral and tricuspid valves have been found adequate for all clinical situations.

Basically, the frames for aortic and atrioventricular valves are similar. However, for the smaller size frames (16 to $20 \mathrm{~mm}$ ) the prongs are splayed in order to increase the outflow or secondary orifice of the valve.

COLLECTION AND PRESERVATION OF TISSUE The pericardium from calves 8 to 16 months old is obtained

1Hypodermic Services Ltd., 1 Headlands Road, Liversedge, Yorkshire 
immediately after slaughter and immersed in sterile cold saline. From this moment on, aseptic techniques are used and all material, instruments, solutions, and containers are presterilized. Strips of tissue of the appropriate size for the valve are cut from the anterior aspect of the pericardial sac in order to obtain the most uniform thickness. The tissue is cleaned only by careful sharp dissection and its thickness is measured with a micrometric gauge.

For attenuation of the antigenic potential and for sterilization and fixation of the pericardial tissue, the method described by Carpentier and Dubost (1972) is used. The strips of pericardium are placed in Hanks' solution for at least three hours. The tissue is then transferred to a solution of 1 part $3 \%$ sodium metaperiodate and 2 parts Hanks' solution and maintained for 24 hours. Next, the tissue is placed for one hour in $1 \%$ ethylene glycol in Hanks' solution and is finally transferred in a glutaraldehyde solution ${ }^{1}$ in which it is kept for from two to six weeks.

After 10 to 14 days' fixation in glutaraldehyde the tissue is mounted on the frame and the valve is left in freshly prepared glutaraldehyde solution for another period of one to four weeks after which it is inspected and finally transferred in a solution of buffered (pH 5.6) 4\% formaldehyde until used. All solutions used for the treatment of the tissue are filtered through Millipore filters G.S., sterilized, and kept continuously at $4^{\circ} \mathrm{C}$.

The strips of pericardium are immersed in the different solutions by suspension in special containers in such a way that they are continuously bathed by the solution. During the whole process of chemical treatment the containers with the tissue are kept in the dark at $4^{\circ} \mathrm{C}$.

CONSTRUCTION OF VALVES A prepared piece of pericardium is tailored to the required size (Table). The free margins of the short sides are sewn together for $4 \mathrm{~mm}$, using a double, continuous 4-0 Mersilene suture, thus producing a partially completed cylinder

T A B L E

SIZES OF PERICARDIAL TISSUE FOR VALVE CONSTRUCTION

\begin{tabular}{|c|c|c|c|}
\hline \multirow{2}{*}{$\begin{array}{l}\text { Internal Diameter } \\
\text { of Frame Support } \\
\text { (mm) }\end{array}$} & \multicolumn{2}{|c|}{ Pericardial Strip } & \multirow{2}{*}{$\begin{array}{c}\text { Internal Diameter of } \\
\text { Heart Valve Annulus } \\
\text { to accept the Graft } \\
\text { (mm) }\end{array}$} \\
\hline & $\begin{array}{l}\text { Length } \\
\text { (mm) }\end{array}$ & $\begin{array}{l}\text { Width } \\
\text { (mm) }\end{array}$ & \\
\hline $\begin{array}{l}16 \\
18 \\
20 \\
22 \\
24 \\
26 \\
28\end{array}$ & $\begin{array}{r}73 \\
80 \\
85 \\
89 \\
95 \\
100 \\
107\end{array}$ & $\begin{array}{l}22 \\
22 \\
25 \\
30 \\
35 \\
35 \\
35\end{array}$ & $\begin{array}{l}22 \\
24 \\
26 \\
28 \\
30 \\
32 \\
34\end{array}$ \\
\hline
\end{tabular}

1Preparation of glutaraldehyde solution: A 1/15 M phosphate buffer is prepared $\left(9.07 \mathrm{~g}\right.$ monobasic potassium phosphate $\left(\mathrm{KH}_{2}, \mathrm{PO} 4\right.$ mol. wt. 136-09)' in $800 \mathrm{ml}$ of sterile distilled water). The pH of the solution is adjusted to $7 \cdot 4$, using approximately $1 \mathrm{~N}$ sodium hydroxide. The volume is brought to $1,000 \mathrm{ml}$ with sterile distilled water. To $974 . \mathrm{ml}$ of this buffer $26 \mathrm{ml}$ of a $25 \%$ solution of glutaraldehyde in water (J. T. Barker Chemical Co.) is added, and the entire solution is filtered through a Millipore filter G.S.

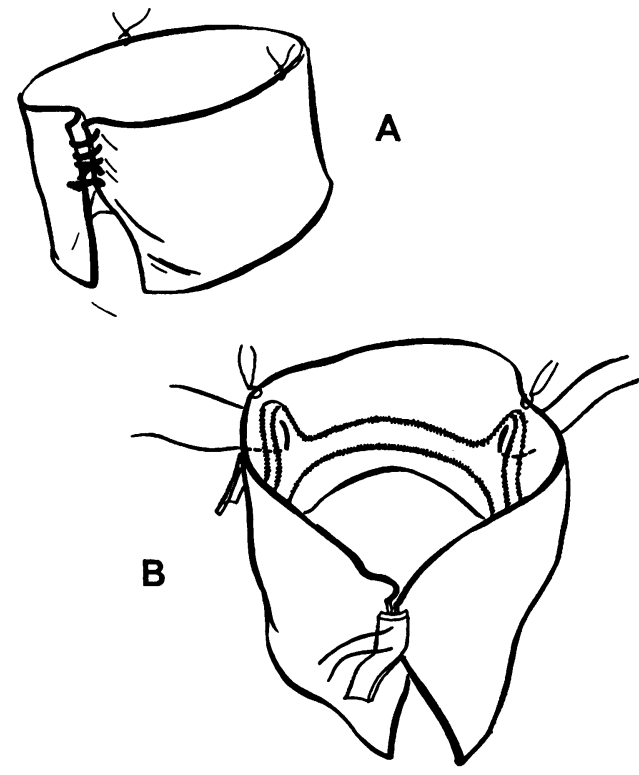

FIG. 2. (A) The short sides of the pericardial strip are sewn together, producing a partially completed cylinder. The upper end of this cylinder is marked at three equidistant points with fine sutures. (B) The pericardial cylinder is attached to the top of the prongs. The stitches are tied over Teflon strips.

(Fig. 2A). The smooth visceral surface of the pericardium becomes the inflow side for atrioventricular valves and the outflow side for aortic valves.

The upper end of the cylinder, which becomes the free edge of the valve cusps, is marked at three equidistant points with 5-0 sutures. These points are determined by placing the cylinder of tissue on a graduated Teflon cone. This manoeuvre is repeated several times in order to establish with great accuracy these points. One of the three points is the original suture line of Figure 2A.

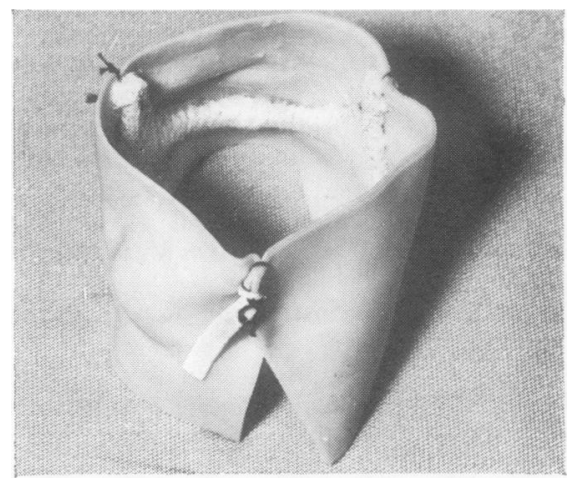

FIG. 3. Same view as in Figure 2B. 
The cylinder is then placed on the outside of the frame, and the three commissural points are sutured to the top of the prongs with 4-0 Mersilene (Figs. 2B and 3). The sutures pass through the perforations at the top of the prongs, through the tissue, and finally through a Teflon strip. The free edge should be $1 \mathrm{~mm}$ above the apex of the prongs. The next suture is applied as shown in Fig. 4A and the prongs are completely covered with tissue.
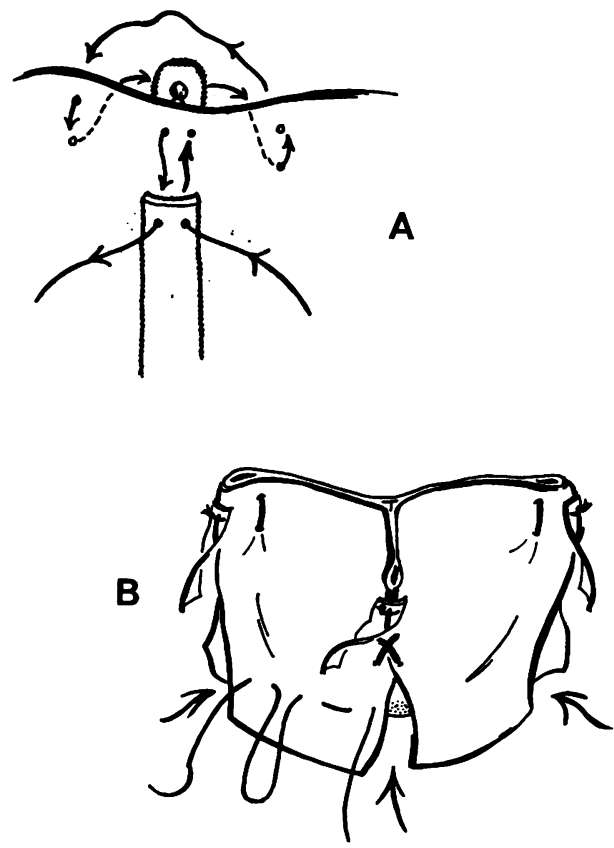

FIG. 4. (A) Schematic view of the suture attachment of the tissue to the top of the prongs. (B) The pericardial tissue is incised vertically at the commissures, and its suturing to the base of the frame proceeds.

The apposition of the free margins of the cusps should be perfect at this stage. Three millimetres depth of apposition of the free margin is adequate to produce competence under physiological pressure.

To allow creation of the ideal shape of the cusps, the pericardium is incised vertically at the commissures, as far as the original commissural stitch (Fig. 4B). The cusps are allowed to assume their definitive shape without any digital pressure. The base or inflow margin of the tissue is then sutured to the ring of the frame by a continuous running stitch (Figs. 4B and 5). The suture continues round the full circumference of the valve to include all three cusps. This suture line is repeated and at the same time the commissural incisions are carefully closed (Fig. 6A).

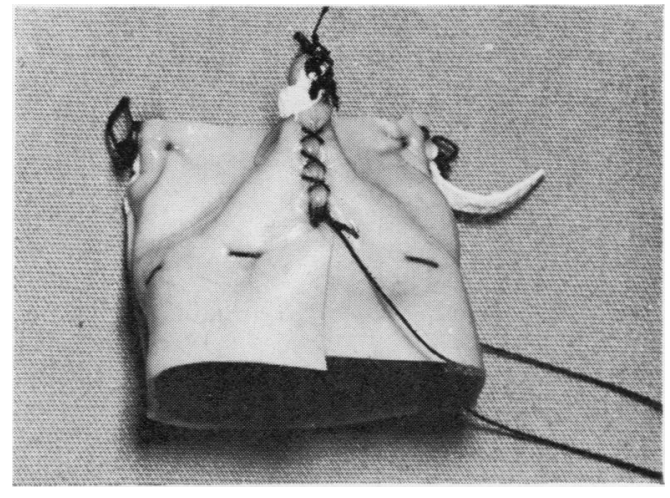

FIG. 5. Same view as in Figure 4B.
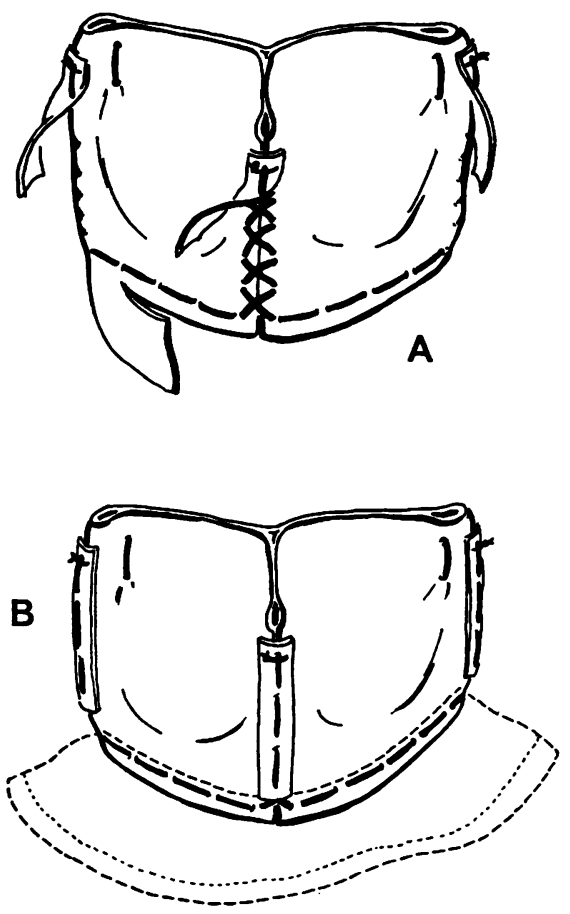

FIG. 6. (A) The fixation of the pericardium to the base of the frame is completed and the commissural incisions are sutured. $(B)$ The commissural attachments are reinforced with a vertical suture line through the Teflon strips.

Finally, a vertical running stitch is inserted which passes through the perforations of the prongs, the pericardium, and the Teflon strip (Figs 6B and 7).

The redundant tissue at the inflow margin of the valve, below the frame, is removed, and the Dacron skirt is attached to the valve by a continuous suture 


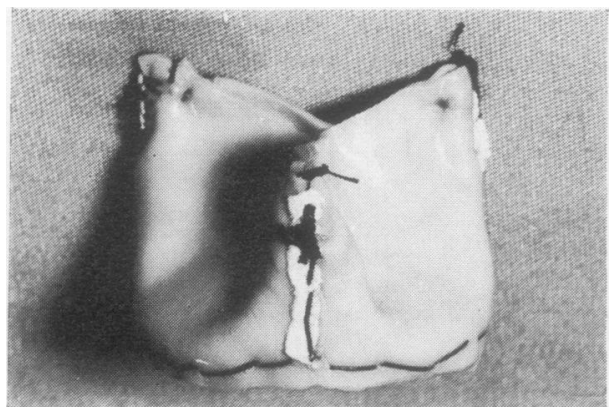

FIG. 7. Same view as in Figure 6B.

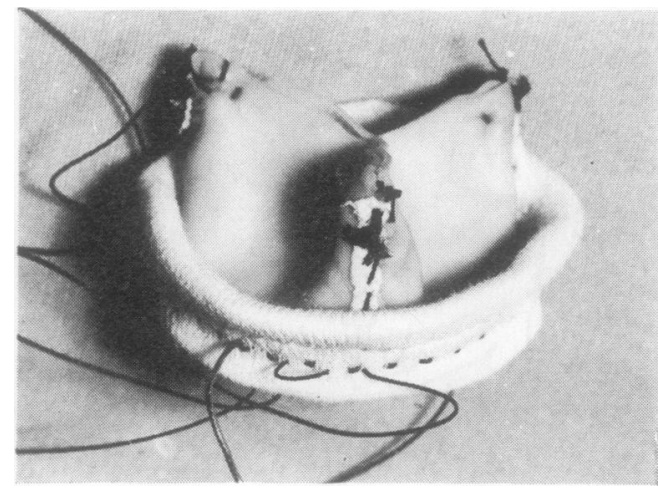

FIG. 8. The sewing rim is being sutured to the mounted valve. The stitch incorporates the pericardial tissue.

which follows the line of stitches at the base of the frame. This suture incorporates the pericardial tissue and completes the construction of the valve (Figs 6B and 8).

During the whole process of valve fabrication the tissue is moistened with glutaraldehyde solution.

This technique can be used with other tissues for the construction of frame-mounted three-cusp valves.

\section{DISCUSSION}

Since 1969 the shape of the supporting frame as well as the technique of valve construction have been modified in order to simplify the manufacture of the valve and to increase the safety of the procedure.

Clinical results and experimental work in circulatory rigs and pulse simulators have elucidated several aspects of frame-mounted tissue valve function and have contributed to improvement in valve construction (Ionescu et al., 1972; Ionescu et al., 1974; Swales et al., 1973; Holden, Pohlner, Catchpole, and Ionescu, 1974).

Valves with a diameter greater than $28 \mathrm{~mm} \frac{\bar{D}}{\bar{c}}$ when made of preserved tissue require a flow $\overrightarrow{\mathbb{D}}$ higher than 51 . per minute to ensure complete $\varrho$

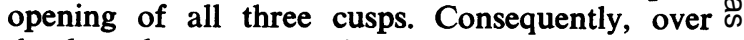
the last three years valves smaller than $28 \mathrm{~mm} \vec{\circ}$ have been used for mitral or tricuspid replacement, and the majority were $24 \mathrm{~mm}$ in diameter.

No significant difference in flow rate and pressure gradient necessary to open the cusps was $\vec{x}$ found when the height of the supporting prongs of the valve was varied from 15 to $22.5 \mathrm{~mm}$. For clinical use in the atrioventricular positions the $\rightarrow$ height of the prongs was $19 \mathrm{~mm}$ for valves of 0 24 and $26 \mathrm{~mm}$ diameter. This ensures sufficient coaptation of the cusps without encroaching upon $c$ the left ventricular outlet when the valves are used for mitral replacement.

In order to enlarge the outflow diameter of small tissue valves for aortic replacement, the supporting prongs of the frame were splayed.

Although in our clinical series of heart valve replacement with preserved tissue there have not been any instances of graft failure, we consider that perfection in valve graft construction is a prerequisite for long-term function. Consequently, $\frac{\mathrm{D}}{\mathrm{D}}$ the valves should be constructed of tissue with equal thickness for each cusp, and tissue portions containing visible blood vessels should be discarded.

It is an established engineering principle that a sphere or part of a sphere represents the greatest resistance that can be applied against an opposing force. For this reason the cusp profile is made flatter and the angle between the cusp and the supporting frame greater than $45^{\circ}$, thus offering less resistance to flow.

In order to prevent changes in the geometry of the cusps during valve insertion, the suturing rim of the valve is attached to the frame-mounted tissue after completion of the valve.

The durability of preserved, frame-mounted, $N$ heterologous pericardial valves will be established $N$ after prolonged periods of clinical follow-up. Our $\stackrel{\sim}{\mathcal{N}}$ two-and-a-half years' experience with this type of $\omega$ 'bioprosthesis' has been encouraging. None of the 68 pericardial grafts inserted in the aortic (42),

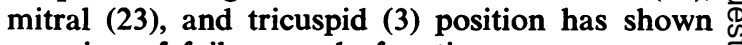
any sign of failure or dysfunction.

The authors would like to express their gratitude to Miss Beryl Walsh, Dr. Said M. Fayoumi, Miss Nancy $\cong$ Evans, and Mr. Leslie Catchpole for help with this $\underset{\mathbb{Q}}{\mathbb{Q}}$ work.

This study was supported by the British Heart Foundation. 


\section{REFERENCES}

Carpentier, A. and Dubost, C. (1972). From xenograft to bioprosthesis: evolution of concepts and techniques of valvular xenografts. In: Biological Tissue in Heart Valve Replacement, edited by M. I. Ionescu, D. N. Ross, and G. H. Wooler. p. 515. Butterworths, London.

Holden, M. P., Pohlner, P. G., Catchpole, L., and Ionescu, M. I. (1974). A pulse simulator for the study of heart valve substitutes. Bioengineering (in Press).

Ionescu, M. I. and Ross, D. N. (1969). Heart-valve replacement with autologous fascia lata. Lancet, $2,335$.
-, Pakrashi, B. C., Holden, M. P., Mary, D. A., and Wooler, G. H. (1972). Results of aortic valve replacement with frame-supported fascia lata and pericardial grafts. Journal of Thoracic and Cardivascular Surgery, 64, 340 .

$\longrightarrow$ - Mary, D. A. S., Bartek, I. T., and Wooler, G. H. (1974). Replacement of heart valves with frame-mounted tissue grafts. Thorax 29, 56.

Swales, P. B., Holden, M. P., Dowson, D., and Ionescu, M. I. (1973). Opening characteristics of three-cusp tissue heart valves. Thorax, 28, 286. 